Diabetes and The Brain. 2009. Edited by Geert Jan Biessels, José A. Luchsinger. Published by Humana Press. 473 pages. C\$225 approx.

\section{Rated thts}

This multi-authored compendium is a trans-atlantic effort edited by two neurologists - one from The Netherlands (Dr. Biessels) and the other from The United States (Dr. Luchsinger). The contributors are from The Netherlands, The United States and The United Kingdom. The book is divided into five parts. Part I, in two chapters, gives an excellent overview of Type 1 and Type 2 diabetes mellitus for the neurologist. For those of us who have been away from general internal medicine for more years than we might care to remember, this is a helpful update. Part II provides a useful overview, for the diabetologist or internist, of issues related to diabetes and the brain: acute ischemic stroke, neuropsychological assessment

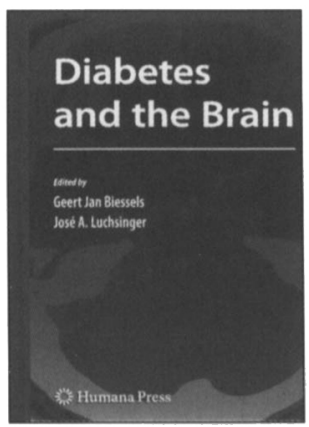
and the clinical evaluation and treatment of cognitive dysfunction and dementia. While the section on acute ischemic stroke would be particularly useful for residents in internal medicine who are rotating on the in-patient Endocrinology consultation service, the other two chapters are probably of much less interest to anyone other than those involved in cognition and dementia. Parts III and IV deal with the acute cerebral effects of diabetes and the longterm cerebral complications respectively. The Chapter on Hyperglycemia in Acute Stroke provides a very nice summary of "where we are at" with respect to this question. Unfortunately, for such a common conjunction, that is, hyperglycemia and stroke, there is very little to guide the clinician, in an evidence-based way with regard to treatment, aside from commending monitoring to the clinician and treatment if the blood sugar exceeds 10.0 $\mathrm{mmol} / \mathrm{L}$. Even then, we don't know how aggressive we should be or whether it helps to be aggressive. While the chapter on Ketoacidosis and Hyperglycemic Hyperosmolar State is good, the figures, unfortunately are poorly reproduced. Figure 1 is only just legible albeit fuzzy but Figure 2 suffers from being illegible in some of the boxes and tables. The final section, Part V, looks at animal models of diabetes, stroke, and alterations in blood sugar, the pathobiology of diabetic encephalopathy in animal models and the role of insulin resistance in age-related cognitive decline and dementia. It will be of interest mainly to clinical neurologists or diabetologists working in this particular area.

For the general neurologist in community practice, this book, like the curate's egg, is "good in parts"; however, at its list price it is not likely to find a home in a personal library. It would severe as a useful reference book in the library of an academic medical centre-especially one with programmes in diabetes, stroke, and cognitive neurology.
Why We See What We Do Redux. A Wholly Empirical Theory of Vision. 2011. By Dale Purves and R. Beau Lotto. Published by Sinauer Associates, Inc. 262 pages. C $\$ 60$ approx.

\section{Rated istars}

This book is a strenuous read which attempts to provide an alternate understanding of the structure and function of the human visual system. The authors present evidence in support of their theory that vision is determined by subjective, practical, historical, and species specific associations between images and behaviour. This theory contradicts an apparently prevailing theory that sensory data that is detected, filtered, and processed by neural circuits to assemble an accurate representation of the objects and conditions in the physical world. The authors' efforts are driven by a desire to more accurately model aspects of the phenomenology of vision that are not well explained by the generally accepted impression that we see the world as it is.

For most neurologists interested in learning more about the visual system, I would suggest starting to read this book at the end. There is an excellent appendix which is a basic review of visual system structure and function, including the cornea, lens, retina, and central visual pathways. Even as a neuro-ophthalmologist I found the appendix of the book to be refreshingly clear and, in contrast to the rest of the book, rewarding because of its familiar concepts. On the other hand, I found the main chapters of the book to be nearly cacographic, and had to read and re-read most paragraphs with heavy use of the glossary, in order to try to

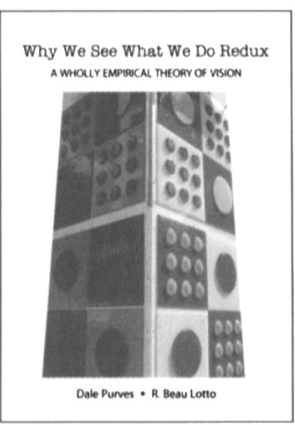
follow what the authors were saying. I

am not sure if that reflects badly on me as a clinician interested in vision science; however, my impression is that the authors are presenting their arguments to a very specific subset of advanced vision scientists who stubbornly adhere to a theory of vision that suggests perceiving the world as it is results from neuronal circuitry that reconstructs a representation of the external world according to the rules of logic and neuroanatomy. The "inverse optics problem" refers to the "impossibility of knowing the world directly by virtue of the light patterns projected onto the retina." This problem is addressed through a series of confusing arguments laid out chapter by chapter regarding visual perception, light stimuli, color vision, object shapes, angles and sizes, depth and distance perception, and seeing motion.

I am passionate about the visual system and have some elementary fluency in the language of vision science, but I found this book to be tough sledding. Even some of the "simple analogies" employed seemed to call into question my adequacy as a percipient being. On the one hand I wanted to plead with the authors to find an easier way to convince me of what they were trying to say, and on the other hand I thought they were merely making the obvious convoluted and esoteric. I may be too practical and judgmental as a reviewer to do this book justice, and there may be some who will find it a beautiful theory of vision; nevertheless, (and I am sure the authors would concur) beauty is in the brain of the beholder. 